\title{
SÔBRE UM CASO DE GLOMÉRULO-NEFRITE LIPOIDOFÍLICA
}

\author{
J. I A MOS J I I I I \\ (Ruintoanis(a)
}

O caso de que vamos tratar tivemos ocasião de observar na enfermaria do Prof. Rubião Meira em um dos leitos a cargo do Dr. Jairo Ramos, e por haver algo interessante no seu estudo, trazemol-o a este Departamento.

Trata-se de um caso de Glomérulo-nefrite mixta, que Munk prefere se dê a terminologia de Glomerulo-nefrite lipoidofílica, especificando dessa maneira a àssociação do processo inflamatôrio com a entidade nosográfica já bem estabelecida nas suas linhas diagnósticas - a Nefrose lipóidica.

Tomámos a nomenclatura do cientista alemão por ser mais explícita, compreensível principalmente para a diferenciação da glomérulo-nefrite crônica, que sem a associação do processo degenerativo, Munk denomina de Cirrófila.

Ainda, com Rosemberg, a denominação deve ser pelo processo inflamatório, pois embora seja o quadro nefrótico o dominante, como acontece com o caso em apreço, a terminologia assim seguida dá o conhecimento da diferenciação dos prognósticos, que como se sabe é, sem duvida, mais sério para a afecção inflamatória.

Passaremos á observação, em resumo, relatando sómente

(1) Trabalho apresentado no Departamento Cientifico em 3 de H.... de 1.73; 
aquilo de positivo para o raciocínio diagnóstico, e em seguida, tambem em resumo, a evolução e tratamento, e para finalizar os comentários sôbre o caso.

\section{Observação:}

F. K. - Hungaro, casado, lavrador, 46 anos. Entrada 16-7-34 Saida 6-1-35. Ila. M. H.

Queixa e duração: - Inchaço em todo o corpo, urinas diminuidas em quantidade e pouca falta de ar. Doente ha 8 dias.

H. P. M. A.: - Sempre teve bôa sau'de até Junho do ano passado (1934), quando teve pela primeira vez inchaço nos tornozelos e pernas, acompanhado de oligúria, porém, a urina era de côr amarela sem nunca ter notado côr averm.lhada. Interrogado convenientemente não tinha dipnéia de esfôrço nem asma cardíaca.

Internou-se na 6a. M. H. onde em poucos dias melhorou saíndo completamente bom.

Dez dias depois novamente teve o mesmo inchaço e mais essa vez internou-se na 6a. M. H., saindo depois de 30 dias completamente bom, sentindo-se bem.

Nove mezes depois novamente teve o mesmo inchaço, agóra tomando tambem as coxas e lombos acompanhado de oligúria, tendo a sua urina a mesma côr amaréla de sempre.

Internou-se dessa vez na la. M., H., e aí permanecendo pelo espaço de um mès, findo o qual saiu completamente desinchado e sentindose bem.

Dez dias depois notou que novamente se inchava começando pelos pés e progressivamente o inchaço tomou todo corpo, até que no $4 .^{\circ}$ dia era tal o inchaço que a sua marcha era dificultada sentindo um pouco. de falta de ar.

Durante todos esses acessos nunca notou urinas avermelhadas, assim como nunca teve dôres de garganta, febre ou resfriados frequeotes, relatando mesmo ser essa a primeira moléstia em sua vida.

Desses acessos o mais intenso foi justamente esse último, com o qual o doente entrou para a enfermaria, ficando aos nossos cuidados. importante.

Do interrogatorio sobre os aparelhos e antecedentes nada ha de

Erame geral: - Anasarca sem cianose ou turgecencia venosa, nem circulagão colateral, palidez acentuada.

Posição no leito: - O tronco forma com o leito um angulo aproximadamente de 45 gráus. 
Não ha fócos de infecção visíveis.

Exame físico: - Revelou de anormal e importante o seguinte:

- Aparelho respiratório: ligeira dispéia inspiratória, sem taquipnéia, frêmito tóraco-vocal abolido nas duas bases, massicez evidente em ambos os hemitorax desde os ângulos inferiores das omoplatas até ás bases, havendo idêntica massicez nas fases laterais e anteriores. $O$ desnivelamento da massicez da face anterior era notável com o decúbito dorsal, tornando possível delimitação da área cardíaca. A ausculta revelava sómente diminuição da respiração nas zonas da massicez.

- Aparelho cárdio-vascular: pela inspecção e palpação, nada conseguimos obter.

A percussão do coração foi possivel pelo desnivelamento da massicês da face anterior do torax com decúbito dorsal; a área cardíaca não se achava aumentada. A ausculta revelou bulhas abafadas. Pulso regular em tempo e amplitude com a frequencia de 60.

P. A. - Mx $114 \times$ Mn 96 (Tycos)

- Abdomen: havia grande edema da parede semelhante ao do torax, sinal de onda presente, massicez movel, não sendo possivel a palpação das visceras abdominais.

Eate foi o exame físico realisado á entrada do doente na enfermaria (7-7-34).

Depois do doente completamente desinfiltrado e absorvidos os seus hidrotorax, realizámos novo exame, 24-10-34) e de fato a área cardíaca não estava aumentada assim como a $\mathrm{P}$. A. não se modificara.

- Os exames de laboratotório realisados logo em seguida, resultaram o que já se esperava para o processo degenerativo renal:

Hipoproteinemia, inversão da fórmula Serino-globulina, Hipercolesterinemia, aspeto pseudo-quiloso do soro e transudatos, Hemossedimentação aumentada, ausência de retenção urêica $(0,30 \%$ ), Albuminúria, Oligúria e Cihindrúria. Entretanto, a densidade das suas urinas era de 1008 - Hipostenúria (contra o que devia acontecer na Nefrose lipoídica pura em que ha Hiperestenúria) e no sedimento, além dos corpúsculos bi-refringentes de Munk, havia hematias e cilidros granulosos e hialinos.

Taxas normais Taxas obtidas

$\begin{array}{lrr}\text { Proteinas totais } & -7.4 \% & \text { Proteinas totais: } \\ \text { Serina - } & 4.6 \% & 4.9 \%-\text { Dr. A. Cintra (18.7.34). } \\ \text { Clobulina - } & 2,7 \% & 4.5 \%-\text { Dr. Milton Amaral (1.9.34). } \\ & \text { (Epstein) } & \end{array}$




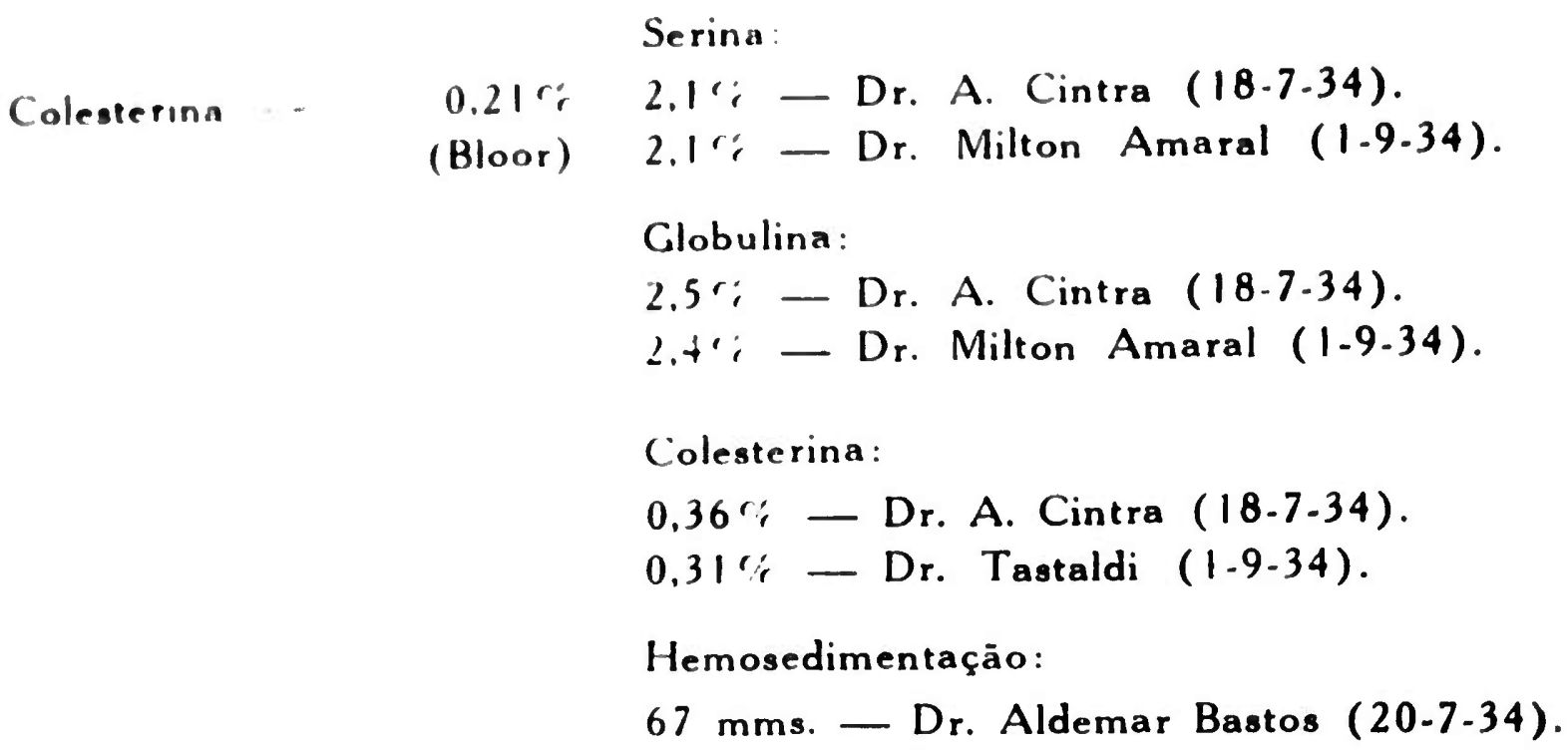

\section{Evolução:}

Foram feitos repetidos exames de uréia no sôro sanguíneo variando entre $0,30 \quad 0,90 \%$, embora a dieta fosse hipoazotada. As urinas tiveram sua densidade entre $1008-1014$ e por várias vezes o sedimento revelou hematias na media de 4 por campo. Uma P. C. (8-12-34) demonstrou a densidade variando entre 1004 1007 - Isostenúria - e a diminuição de $1 \mathrm{~kg}, 100$ de peso. As urinas eram turvas, côr amarélo palha e a sua turvação permanecia mesmo após a filtração. A P. A. nunca foi de 120 a pressão sistólica, e o exame dos fundos oculares - normal. $R$. Wassermann - negativa.

\section{Tratamento:}

O tratamento resumiu-se em repouso, restrição de líquidos, diéta acloretada e hipoazotada, a diuréticos para a eliminaçāo dos edemas.

Este último foi o que chamou mais a atenção devido aos surpreendentes resultados obtidos. (Fig. 1).

A principio foram usados - Salirgan e Novurit - que aumentaram a diurese sómente no dia da sua aplicação. Esse aumento da diurese foi, entretanto, medíocre em - Jmparação ao tratamento instituido em seguida - a diurese pela acidose provocada. Usamos a solução de $(\mathrm{AzH} 4) \mathrm{Cl}$ - cloreto de amonio - a $20 \%$ na dose de $75 \mathrm{cc}$. por dia, que equivale a 15 gramas de sal. Fizemos esse tratamento durante 22 dias a a Reserva 


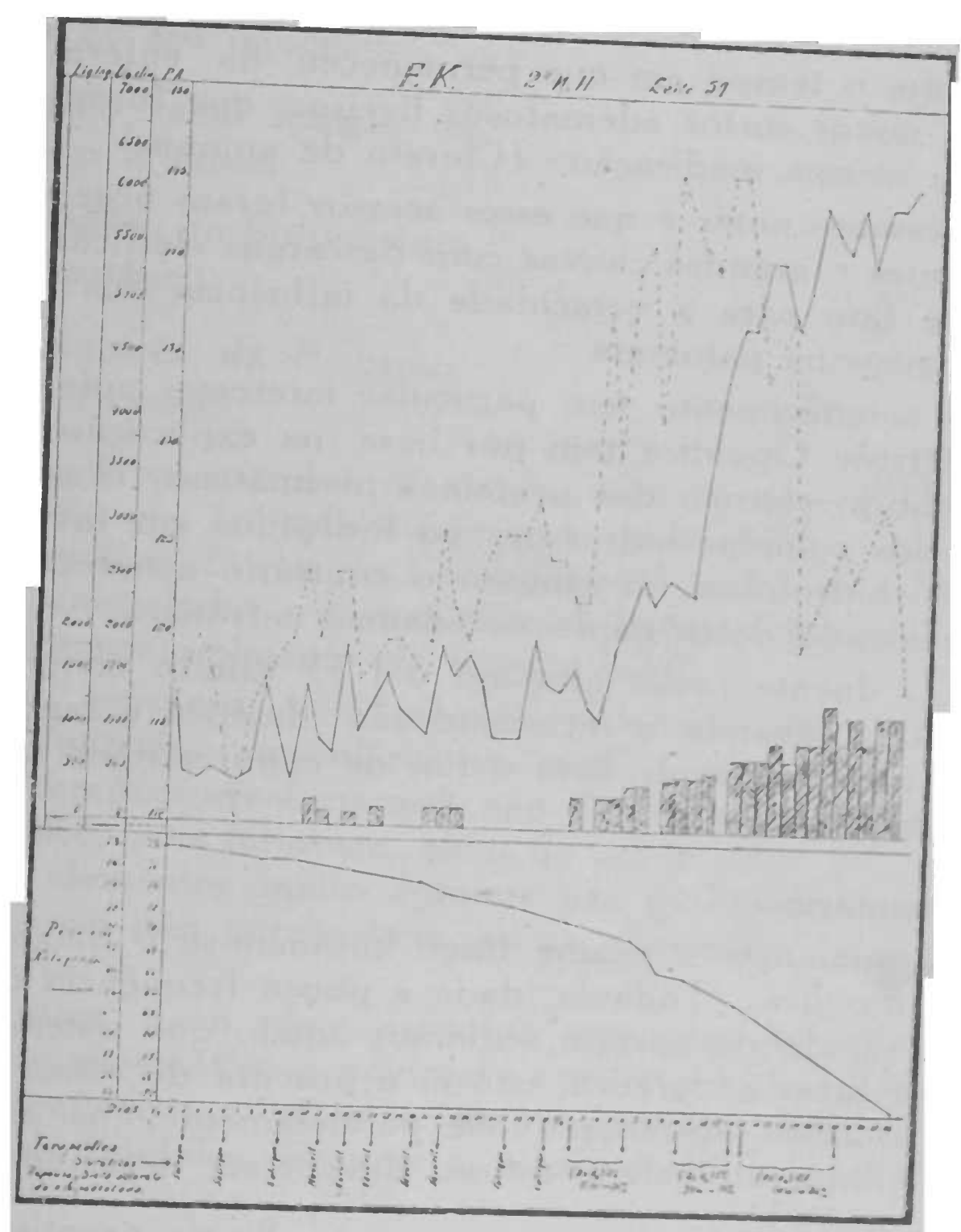

(Fig. 1) 
Alcalina que era antes de $53 \%$ passou a ser $50,53 \%$ após o tratamento, e portanto sem alterações apreciáveis.

Foi grandemente animador o resultado, como se observa no gráfico, pois em 25 dias o doente diminuiu de 18 quilos o seu péso (72-54), em quanto com os outros diuréticos - Salirgan e Novurit - a diminuição foi de 10 quilos no espaço de 1 mês e meio.

Durante o tempo em que permaneceu na enfermaria teve ainda tres novos surtos edematosos ligeiros, que foram combatidos com a mesma medicaçāo (Cloreto de amonio).

Interessante notar é que esses acessos foram observados nos dias seguintes a grandes chuvas com descargas elétricas, corroborando esse fato para a veracidade da influência dos fenômenos metereológicos na patologia.

Este acontecimento tem particular interesse, pois a patogenia da Nefrose Lipoidica tem por base, na explicação de Munk, o desequilíbrio elétrico das proteinas plasmáticas, ocasionando a inversão dos coloides hidrossoes ou hidrófilos em favor dos hidrogeis ou hidrófobos no sangue; o contrário aconteceria no tecido, explicando desse modo os edemas nefróticos.

- O doente pediu alta em 6-1-35 saíndo completamente desinfiltrado, levando a recomendação detética a seguir e para voltar periodicamente com o fim de continuarmos a evolução da sua molestia.

\section{Comentarios:}

Pela anamnese e exame físico impunha-se o diagnóstico de Nefrose Lipoídica. Todavia, dada a pouca frequência dessa moléstia em estado de pureza, seguimos aquilo que sistematicamente se deve fazer na prática, isto é, a procura de sinais que positivam o processo degenerativo e paralelamente, os sinais que, proprios Glomérulo-nefrite difusa, devem ser negativos.

Sinais positivos

1 - Grandes edemas e oligúria.

2 - Lipoidúria e cilindrúria intensas

3 - Albuminúria com hiperestenúria

4 - Lipemia e hipercolesterinemia
Sinais negativos

1 - Ausência de alterações cardíacas e vasculares (hipertensão arterial e hipertrofia cardíaca).

2 - Fundos oculares inalterados

3 - Hematúria ausente Sinais positivos 
5 - Aspeto pseudo quiloso do sôro sanguineo e dos transudatos

6 - Hlpoproteinemia c o m inversão da fórmula serino-globulina e alteração de seu quociente

7 - Função renal íntegra ou pouco alterada

8 - Aumento do fibrinogênio no sangue

9 - Diminuição da P. osmótica do sôro
4 - Ausência de retenção azotada (Azoto não protêico)

5 - Ausência da uremia e só muito raramente eclampsia.

Ora, tivemos todos os sinais positivos com exceção da hiperestenúria que foi substituida por Isostenúria, a qual junto á renteção urêica, Prova de Concentração má, poliúria obrigatória e urinas amareladas e turvas mesmo após a filtração, evidenciavam o comprometimento da função renal.

Era, portanto, uma glomérulo-nefrite crônica já em fase de Rim contraído secundário associada a uma nefrose lipoídica.

E' compreensível porquê não foi feito o diagnóstico pelo exame físico, pois faltavam, além de um passado infeccioso qualquer, os elementos muito comuns nas glomérulo-nefrites e que o nosso caso não apresentava - as alterações cardiacas e vasculares.

E' pois, bem demonstrativo este caso da necessidade de um exame sistemático e completo com o fim de se não caír em erros diagnósticos e prognósticos, devendo-se sempre em casos de Nefrose- lipoídica procurar os sinais positivos e negativos des8a afecção.

Sem o intuito de discutir a patogenia do caso, acenaremos somente que a doutrina defendida por Munk explica não só a sua patogenia, como fornece base á compreensão do modo de agir do diurético com que tão bons resultados tivemos - o (AzH4) $\mathrm{Cl}$.

Assim, todos os sinais na Nefrose-lipoídica são explicados direta $e$ indiretamente pelo desequilibrio elétrico dos colóides do organismo - proteinas e lipóide - que guardam entre si estreitas relações; e os da glomérulo-nefrite difusa pela consideração de que é uma molestia capilar geral, recebendo mesmo o nome dado por Kylin de "Capilariopatia universalis" 
O desequilibrio elétrico dos colóides se resolve na hipoproteinemia, inversão da fórmula serino-globulina, lipemia, etc., que sāo de grande valor na gênese dos edemas nefróticos.

Ora se usarmos uma substância como o $\left(\mathrm{AzH}_{4}\right) \mathrm{Cl}$ que vai justamente, provocando uma acidose, aproximar do equilíbrio elétrico esses colóides, os edemas deixarão de existir. Este é o raciocínio físico-químico mais provável, pois sendo o ( $\left.\mathrm{AzH}_{4}\right)$ $\mathrm{Cl}$ uma substância que ao se dissolver liberta hidrogenions e oxidrilions, com predominância dos primeiros, por mecanismo, secundário devido á hidrólise, ha introdução de cargas ilétricas no organismo.

Achamos ser esta a interpretação mais lógica com os princípios físico-químicos, e não como quer Haldane (cit. em L'EQUILIBRIO ACIDO-BASICO DELLORGANISMO E SUE APPLICAZIONI CLINICHE NELLA DIAGNOSI FUNZIONALE DEL RENE - M. Gelera, pag. 113), que acha a reação se processa sómente no interior do organismo, no figado.

Ora, o ( $\mathrm{AzH} 4) \mathrm{Cl}$ já em solução, tal como é administrado, é hidrolisado, e interpretando-se desta maneira não incriminaremos o fígado nesta reação.

O equilíbrio elétrico produzido pela introdução das cargas elétricas é instavel, e está sob a ação continuada da primeira causa, que é justamente o agente etiológico do processo e sôbre o qual reinam ainda duvidas.

$$
\text { *** }
$$

A segunda parte do nosso caso, isto é, o processo inflamatório é explicado pelo comprometimento preferencial do territotório capilar do rim, dando as perturbações da função desse órgão. O mesmo não acontecendo aos outros capilares do resto do organismo, explica o fáto de não termos as alterações cardíacas e vasculares representadas pela hipertrofia cardíaca, hipertensão arterial e modificações dos fundos oculares.

$$
\text { *** }
$$

Julgámos ter demonstrado o que de interessante este caso apresenta, como nos propuzemos no inicio, e que em conclusão é:

$\left.10^{\circ}\right)$ Necessidade do exame sistemático e completo, perquizando todos os sinais, positivos e negativos, na Nefrose lipoídica.

2.) Uma glomerulonefrite crônica difusa incomum sem hipertensão arterial e hipertrofia cardiaca.

3. ${ }^{\circ}$ ) A diurese para a eliminação dos edemas nefróticos pela acidose provocada. 